\title{
Real-life cost savings and capacity improvements on implementation of the new BSG post-polypectomy surveillance guideline
}

The British Society of Gastroenterology (BSG) has recently updated its guideline for post-polypectomy surveillance. ${ }^{1}$ The now defunct 2010 guideline recommended that patients with low-risk adenomas (LRAs) should be offered either 5-year colonoscopy or no surveillance. In our experience, clinical practice tended to continue with colonoscopy surveillance.

Evidence has since emerged demonstrating that patients with LRAs are not at increased risk of colorectal cancer compared to patients with no adenomas detected at colonoscopy, nor to the unexamined general population. ${ }^{2,3}$ As a result, the new guideline recommends that patients with LRAs be followed up by participation in the national Bowel Cancer Screening Programme (BCSP) when eligible, rather than with colonoscopy surveillance. No follow-up is recommended for patients over 75 years old, but colonoscopy surveillance in 5-10 years can be considered for patients with LRAs that are $>10$ years younger than the lower screening age of the BCSP.

We carried out a modelling study to estimate the potential cost savings and capacity that could be generated by implementing the new guideline at our trust.

We conducted a retrospective endoscopy database analysis of patients for whom 5-year colonoscopy surveillance had been requested for LRAs between 2013 and 2018 at a London teaching hospital. We calculated the cost savings using the $2018 / 19$ NHS tariff for diagnostic colonoscopy and an estimate of the histology costs, working under the assumption that one adenoma would be removed and sent for histological analysis in $30 \%$ of patients undergoing colonoscopy surveillance. ${ }^{4,5}$
The first model follows the 2010 guideline: all patients with LRAs undergo 5-year colonoscopy surveillance. The second and third models follow the 2019 guideline. In model 2, colonoscopy surveillance is offered to all patients aged $<45$ years at index colonoscopy, as bowel scope screening is offered in our area. In model 3 , we assume that no patients are offered colonoscopy surveillance, as surveillance in younger patients is not mandated in the new guideline.

There were 1,035 patients identified; with a mean age of 58.5 years (standard deviation 12.6; range 23-97). The potential cost savings and capacity generated by implementing the 2019 guideline for patients with LRAs are displayed in Table 1. Under current practice we will carry out 1,035 surveillance colonoscopies for LRAs over the next 5 years, at a total cost of $£ 438,498$. Implementing the 2019 guideline will lead to an annual cost saving of $£ 75,159$ to $£ 87,699$, depending on the number of patients $<45$ years old offered colonoscopy surveillance, and generate capacity for 177 to 207 additional colonoscopies per year. Using a real patient cohort, we have demonstrated that significant cost savings and capacity improvements will result from the implementation of the new BSG guideline. These savings will increase when the lower screening age of the BCSP is reduced to 50 years, as is anticipated. This is welcome news in the financially constrained NHS, and the generation of additional capacity, at no opportunity cost, will allow endoscopy units to focus their efforts on the patients most likely to benefit.

Table 1. Potential cost savings and capacity improvements of implementing the 2019 British Society of Gastroenterology post-polypectomy surveillance guideline in patients with low-risk adenomas

\begin{tabular}{|c|c|c|c|c|}
\hline Model & $\begin{array}{l}\text { Follow-up with 5-year } \\
\text { colonoscopy, n (\%) }\end{array}$ & $\begin{array}{l}\text { Total local cost } \\
\text { over } 5 \text { years }\end{array}$ & $\begin{array}{l}\text { Local cost saving } \\
\text { over } 5 \text { years }\end{array}$ & $\begin{array}{l}\text { Local colonoscopy capacity } \\
\text { gained over } 5 \text { years, } n\end{array}$ \\
\hline \multicolumn{5}{|l|}{ Model 1} \\
\hline BSG 2010 guideline & $1,035(100)$ & $£ 438,498$ & $£ 0$ & 0 \\
\hline \multicolumn{5}{|l|}{ Model 2} \\
\hline $\begin{array}{l}\text { BSG } 2019 \text { guideline: } 5 \text {-year } \\
\text { colonoscopy offered to } \\
\text { patients }<45 \text { years }\end{array}$ & $148(14.3)$ & $£ 62,703$ & $£ 375,795$ & 887 \\
\hline \multicolumn{5}{|l|}{ Model 3} \\
\hline $\begin{array}{l}\text { BSG } 2019 \text { guideline: No } \\
5 \text {-year colonoscopy offered } \\
\text { to patients }<45 \text { years }\end{array}$ & $0(0)$ & $£ 0$ & $£ 438,498$ & 1,035 \\
\hline
\end{tabular}


BENJAMIN SHANDRO

Research fellow in gastroenterology, St George's University Hospitals NHS Foundation Trust, London, UK

VINCENT CHANG Medical student, St George's, University of London, London, UK

JAI MATHUR

Medical student, St George's, University of London, London, UK

PARKER O'NEILL

Medical student, St George's, University of London,

London, UK

CHRISTOPHER GROVES

Consultant gastroenterologist, St George's University Hospitals NHS Foundation Trust, London, UK

GARETH SADLER

Consultant gastroenterologist, St George's University Hospitals NHS Foundation Trust, London, UK

ANDREW POULLIS

Consultant gastroenterologist, St George's University Hospitals NHS Foundation Trust, London, UK

\section{References}

1 Rutter MD, East JE, Rees C et al. BSG/ACPGBI/PHE Post-polypectomy and post-colorectal cancer resection surveillance guidelines. London: British Society of Gastroenterology, 2019. www.bsg.org.uk/resource/ bsg-acpgbi-phe-post-polypectomy-and-post-colorectal-cancerresection-surveillance-guidelines.html [Accessed 09 October 2019].

2 Click B, Pinsky PF, Hickey T et al. Association of colonoscopy adenoma findings with long-term colorectal cancer incidence. JAMA 2018:319:2021-31.

3 Løberg M, Kalager M, Holme Ø et al. Long-term colorectal-cancer mortality after adenoma removal. N Engl J Med 2014;371:799-807.

4 Longcroft-Wheaton $\mathrm{G}$, Bhandari P. The cost impact of in vivo diagnosis of diminutive polyps: experience from a screening endoscopy programme. Gut 2011;60:A30.

5 Hornung TA, Bevan R, Mumtaz S et al. Surveillance colonoscopy in low-risk postpolypectomy patients: is it necessary? Frontline Gastroenterol 2015;6:77-84.

Address for correspondence: Dr Benjamin Shandro, Department of Gastroenterology, St George's University Hospitals NHS Foundation Trust, Blackshaw Road, London SW17 0QT, UK.

Email: bshandro@nhs.net 